\title{
"DESARROLLO URBANO Y AMBIENTE \\ EN LA CIUDAD DE SAN JUAN, ARGENTINA"
}

Arq. María del Pilar Espinosa*

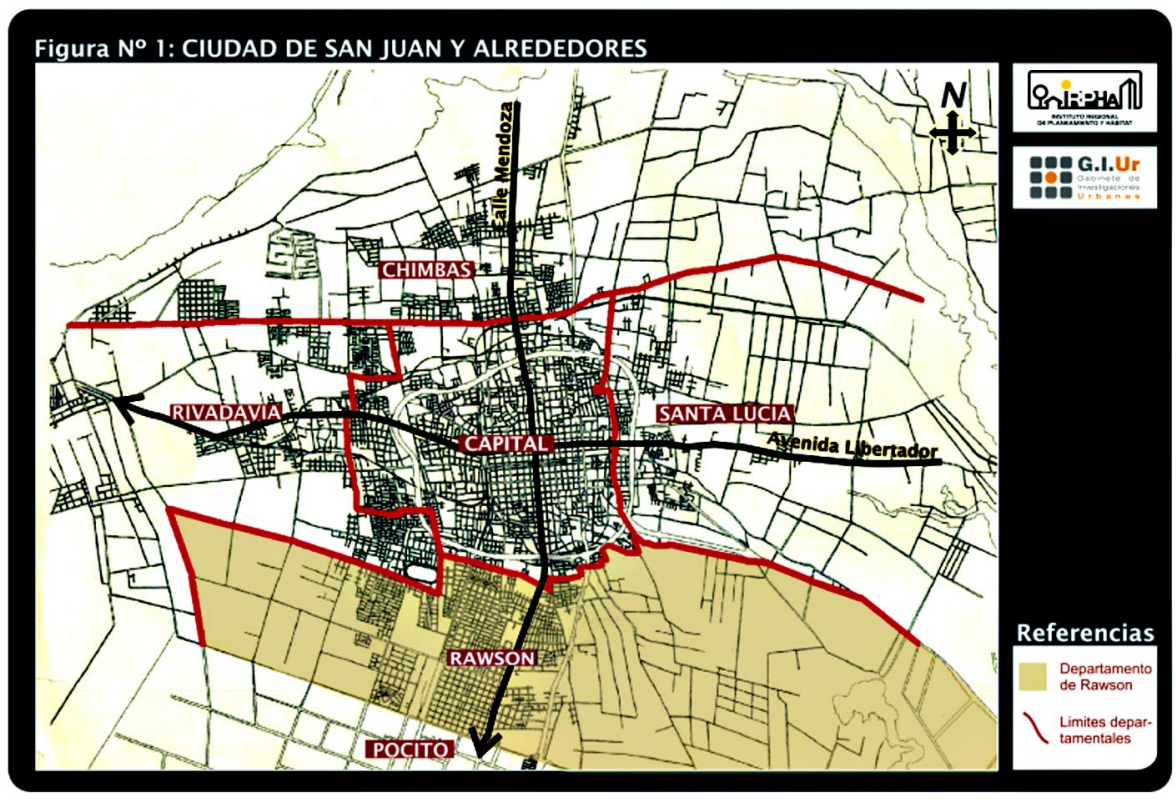

\section{Resumen:}

La ciudad de San Juan posee dos condicionantes del medio natural: la aridez y el sismo (la sismicidad?). La aridez ha condicionado desde su fundación, la evolución y el desarrollo de la ciudad en función de la escasez del recurso "agua". Respecto al sismo (a la sismicidad?), San Juan está ubicado en la zona de mayor actividad sísmica del país como lo demuestran los numerosos terremotos destructivos que la han afectado a lo largo de su historia. Ambos condicionantes se traducen conceptualmente en tendencias contrarias de ocupación del suelo. Así, una adecuada respuesta a la aridez debería producir la concentración de la planta urbana en una superficie reducida debido a la insuficiencia del agua. En tanto que la respuesta al factor psicológico de temor al sismo provoca una ocupación extendida del área urbana. Las intervenciones urbanas enmarcadas dentro de políticas de desarrollo urbano sustentable deberían compatibilizar estas dos tendencias contrapuestas.

En este marco, se plantean como objetivos, contribuir al mejoramiento urbano ambiental del Gran San Juan, con estudios sobre áreas estratégicas susceptibles de admitir intervenciones que propicien el control de la expansión urbana, especialmente en el límite sur. En función de ello generar pautas para el marco normativo del crecimiento y definición del límite urbano.

\section{Palabras Clave:}

Desarrollo Urbano- Ambiente- expansión urbana. 
* Magister Facultad de Arquitectura, Urbanismo y Diseño (FAUD) - Universidad Nacional de San Juan (UNSJ).

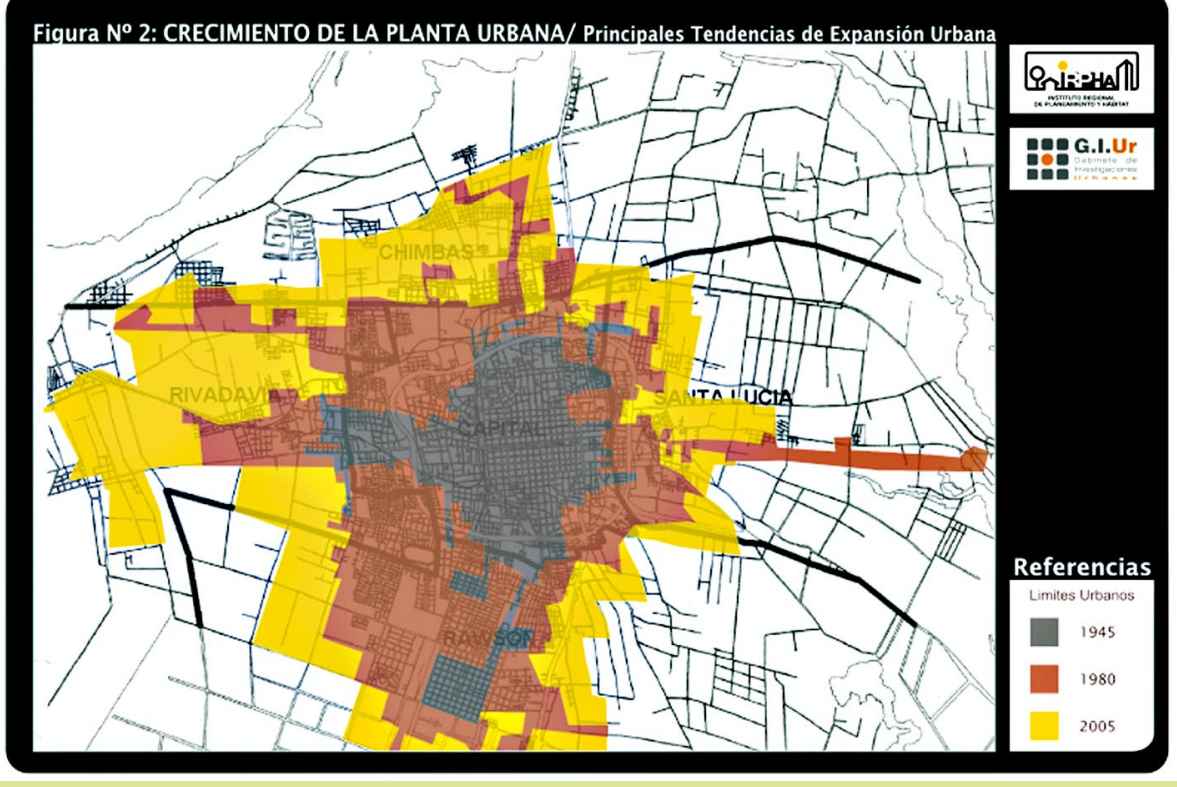

\section{Abstract:}

The city of San Juan has two conditioners of natural means: the dryness and the quakeness. The dryness has conditioned from its foundation, the evolution and the development of the city based on the shortage of the resource "water". With respect to the quakeness, San Juan is located in the zone of greater seismic activity of the country as it is demonstrated by the numerous destructive earthquakes that have affected it throughout his history. Both conditioners are translated conceptually in opposite tendencies of occupation of the ground. Thus, a suitable answer to the dryness should produce the concentration of the population in a reduced territory due to the insufficiency of the water. Whereas, the answer to the psychological factor of fear due to earthquakes causes an extended occupation of the urban area. The urban interventions framed within policies of sustainable urban development would have to make compatible these two opposed tendencies.

In this frame, they are considered objectives, to contribute to the environmental urban improvement of Great San Juan, with studies on strategic areas susceptible of admitting interventions that favour the control of the urban expansion, specially in the south border. Based on them, to generate guidelines for the normative frame of the growth and definition of the urban limit.

\section{Keywords:}

Urban development, environment, urban expansion. 


\section{Problemática actual}

Las ciudades cambian en un proceso de constante transformación y urbanización en forma acelerada, extienden su territorio y amplían sus límites, los que se vuelven cada vez más imprecisos. La ciudad de San Juan, capital de la Provincia homónima, está ubicada en el centro Oeste de Argentina, en el borde oriental de la cordillera de Los Andes. Constituye una conurbación conformada por el Departamento Capital y las áreas urbanas de los Departamentos vecinos de Chimbas, Santa Lucia, Rawson y Rivadavia, denominada Gran San Juan a la que actualmente se incorpora el borde Norte del Dpto. Pocito, en el sur.

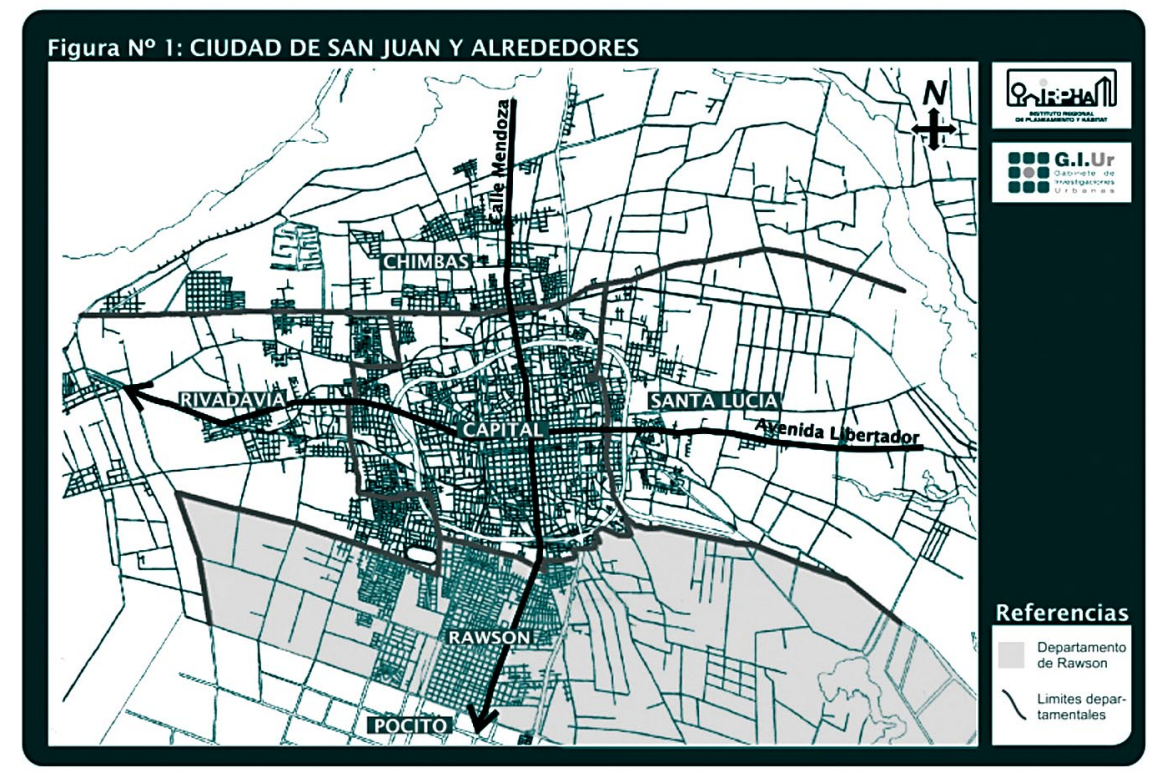

Los dos condicionantes más importantes de su medio natural son la aridez y el sismo. Ello permite caracterizarla como ciudad - oasis, ubicada en zona de alto riesgo sísmico. Ambos condicionantes se traducen conceptualmente en tendencias contrarias de ocupación del suelo. La aridez ha condicionado desde su fundación, la evolución y el desarrollo de la ciudad en función de la escasez del recurso "agua". Una adecuada respuesta a la aridez debería producir la concentración de la planta urbana en una superficie reducida debido a la insuficiencia del agua. Respecto al sismo San Juan, a lo largo de su historia, ha sido afectada por varios terremotos destructivos como consecuencia de estar localizada en la zona de mayor actividad sísmica del país. La respuesta al factor psicológico de temor al sismo provoca una ocupación extendida del área urbana.

Las intervenciones urbanas enmarcadas dentro de políticas de desarrollo urbano sustentable deberían compatibilizar estas dos tendencias contrapuestas.

Este estudio surge de la necesidad de controlar la expansión de la planta urbana del Gran San Juan, la que está produciendo consecuencias tales como la inutilización de tierras de cultivo, el encarecimiento de la infraestructura de servicios y el equipamiento y en general deseconomías de escala. Este problema se produce entre otros motivos por el crecimiento de población, el desaprovechamiento de espacios urbanos internos del área urbana, la baja densidad poblacional y los altos costos de la tierra urbana, especialmente en los sectores centrales de la ciudad. 
En particular el trabajo se centra en el límite sur por la propensión de la planta urbana a la expansión en esta dirección y por la tendencia a la conurbación que se visualiza entre los Departamentos de Rawson y Pocito. Bajo un enfoque ambiental, se considera a la ciudad como una unidad donde se interrelacionan permanentemente los condicionantes que impone la naturaleza, con el medio artificial ó antropizado. Así, el proyecto se orienta a detectar y posteriormente caracterizar los sectores urbanos potencialmente factibles de aplicar estrategias de ordenamiento y mejoramiento urbano ambiental. En este marco, se plantean los siguientes objetivos:

\section{Objetivo General}

Contribuir al mejoramiento urbano ambiental del Gran San Juan, con estudios particularizados de áreas estratégicas susceptibles de admitir intervenciones que propicien el control de la expansión urbana, especialmente en el límite Sur.

\section{Objetivos Específicos}

1. Identificar áreas urbanas deterioradas y aquéllas cuya vulnerabilidad sísmica sea elevada (en el Dpto. Rawson y sector Norte de Pocito), seleccionadas las áreas prioritarias para implementar estrategias de intervención.

2. Seleccionar y evaluar los terrenos factibles de albergar el crecimiento urbano y la densificación urbana de esos sectores.

3. Determinar las estrategias urbanas que se van a implementar, adecuadas a las problemáticas específicas de cada sector, definir zonas para la renovación, rehabilitación, densificación y control del límite urbano.

4. Generar pautas para el marco normativo del crecimiento y definición del límite urbano del Dpto. Rawson.

Metodológicamente el estudio se organiza considerando distintos parámetros urbanos que permiten seleccionar los sectores que se van a intervenir y así, establecer criterios adecuados para la formulación de pautas urbano - ambientales que enmarquen la normativa al respecto. Para ello, el trabajo se ordena en tres etapas operativas:

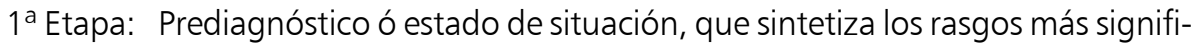
cativos del área urbana de los Dptos. Rawson y Pocito para la selección de áreas estratégicas para intervenir.

2ª Etapa: Diagnóstico específico de las áreas estratégicas seleccionadas.

$3^{\mathrm{a}}$ Etapa: Lineamientos propositivos.

Como procedimiento metodológico en la primera etapa se aplica la técnica DAFO (Debilidades - Amenazas - Fortalezas - Oportunidades) con la cual se obtiene una aproximación al estado de situación del área de estudio. Operativamente las tareas de análisis se apoyan, además, en el uso de un sistema de información geográfica (GIS), lo que permite manejar una importante base de datos en forma interrelacionada, y utilizar las posibilidades que brinda este instrumento computacional, especialmente en su capacidad de búsqueda y de elaboración estadística y cartográfica. Esto permite obtener un marco de trabajo de fácil identificación de las relaciones de las variables urbanas. En función de ello, se trabajará en la $2^{a}$ y $3^{a}$ Etapa correspondiente al Diagnóstico y Formulación de estrategias de intervención urbana. 
Actualmente se elabora la primera etapa de prediagnóstico de este trabajo, que es un proyecto de investigación en curso que se está desarrollando durante el periodo 2006/ 2007 en nuestra unidad académica en forma conjunta con la Dirección de Planeamiento y Desarrollo Urbano de la Provincia de San Juan.

\section{Prediagnóstico o Estado de Situación}

En la primera etapa, que corresponde al prediagnóstico ó estado de situación, se caracteriza la totalidad del área urbana y luego se focaliza el problema en el límite Sur de la misma.

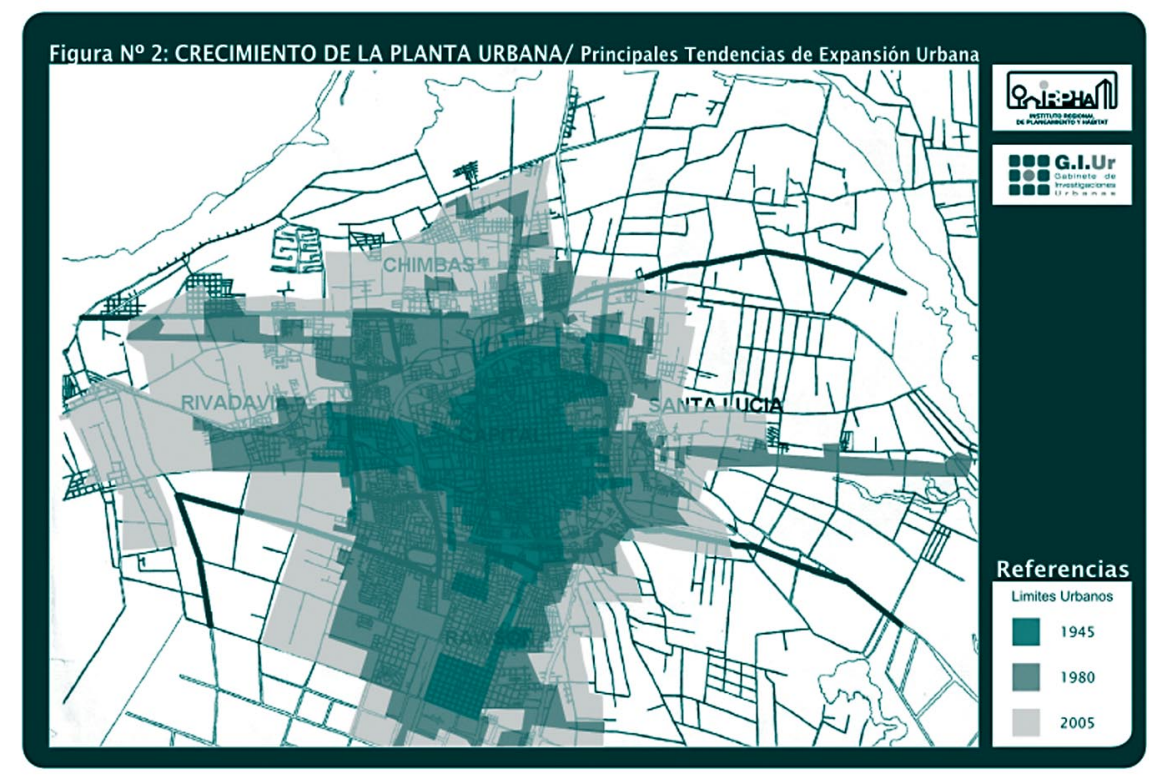

El problema del crecimiento de la planta urbana de la ciudad de San Juan se traduce en el avance sobre tierras agrícolas, produciendo la falta de densificación de sus sectores internos. La subutilización de la tierra se manifiesta por grandes lotes baldíos dentro y en los bordes de la misma. Entre las décadas del 70 y el 80 la planta tenía un área mínima o continuamente urbanizada de 5600 hectáreas con una capacidad vacante de 1.458 has. Se prevé una ampliación de 10.000 has. para expansión futura. Actualmente el área mínima es 8.760 has., siendo el límite urbano propuesto por la Dirección de Planeamiento y Desarrollo Urbano de 10.700 has. aproximadamente. Este crecimiento se ha producido sin agotar la capacidad vacante interna de la planta, por el contrario la misma ha aumentado respecto a las décadas anteriores. El análisis de su evolución en los últimos sesenta años muestra que ha experimentado un rápido crecimiento en extensión con baja densidad, lo que está tendiendo a revertirse en la última década pero sin llegar a niveles óptimos. Ello se manifiesta a través de los siguientes datos:

$\begin{array}{ll}\text { AÑO } & \text { DENSIDAD } \\ 1947 & 59 \mathrm{H} / \mathrm{ha} . \\ 1980 & 44,9 \mathrm{H} / \mathrm{ha} . \\ 1991 & 26 \mathrm{H} / \mathrm{ha} . \\ 2001 & 32 \mathrm{H} / \mathrm{ha} .\end{array}$

Evidentemente, esta densidad de población no puede sustentar la provisión de servicios básicos de infraestructura y su mantenimiento, lo que ocasiona el consecuente encareci- 
miento y la disfuncionalidad de los servicios, especialmente del agua potable debido a la escasez de este elemento.

Pueden mencionarse como algunas de las causas que provocan estas bajas densidades, además de la ya mencionada de temor psicológico al sismo, la especulación inmobiliaria y la construcción masiva de viviendas, destinadas a sectores de medios y bajos recursos económicos. Ello constituyó parte del proceso de reconstrucción de la ciudad luego del terremoto de 1944 para revertir el déficit habitacional, no sólo cuantitativo sino cualitativo, el cual ha ido incrementándose desde entonces.

Estos factores provocan, en algunos casos, los fenómenos urbanos denominados "desarrollo discontinuo" y "desarrollo en extensión", que inciden en los costos económicos, ambientales y en el consumo de recursos naturales sin una clara política de preservación para el no abuso de los mismos y el control del impacto ambiental ocasionado por operaciones de antropización de grandes extensiones de suelo rural.

Históricamente, la expansión de la ciudad a partir del núcleo fundacional se desarrolló a través de los ejes que la vinculaban con la región y con el resto del territorio nacional. El desarrollo de la planta urbana en los últimos años tiene una tendencia notoria hacia el sector Sur, donde se advierte la propensión a la conurbación entre el Dpto. Rawson y el sector Norte de Pocito.

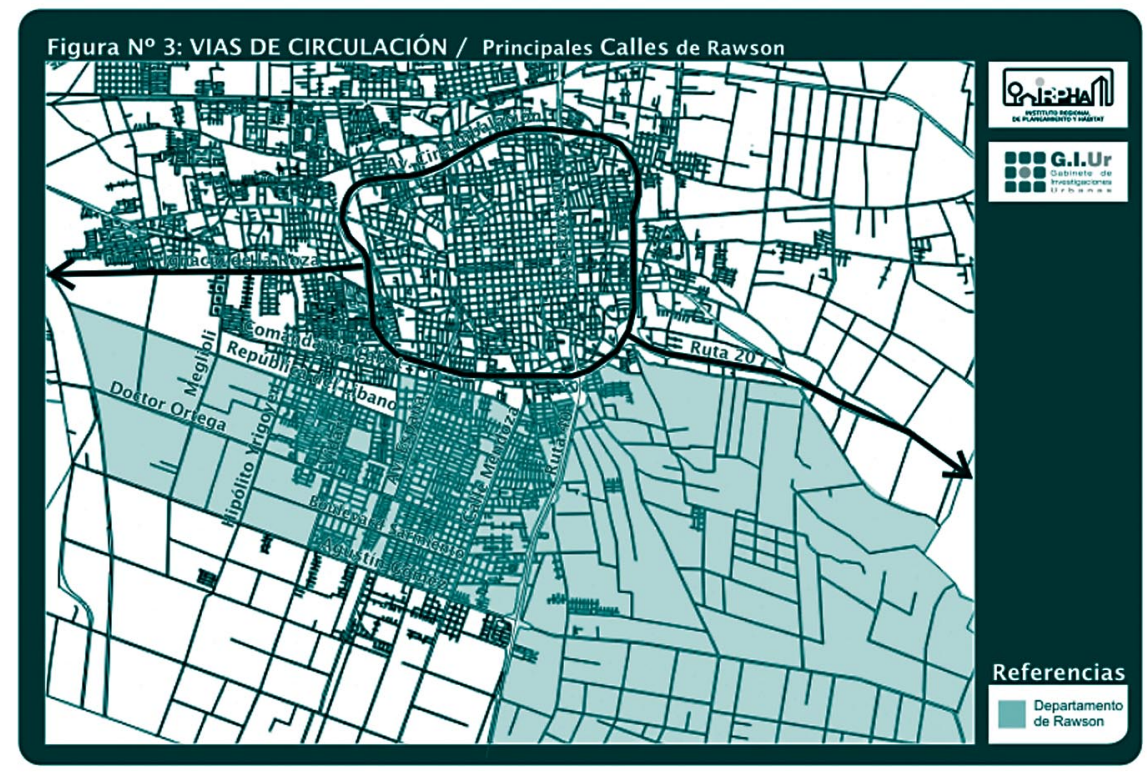

Esto es consecuencia de la consolidación de los ejes de urbanización tradicionales y también por el surgimiento de nuevos flujos de población, de bienes y servicios, energía y comunicación, canalizados a través del principal corredor de conexión con la Provincia de Mendoza. La falta de estrategias en las que se definan áreas prioritarias de expansión urbana favorece la diseminación de desarrollos residenciales privados en torno al trazado de corredores principales tales como Av, Mendoza, Av. España y calle Lemos entre otros, que da cuenta de la necesidad de implementar lineamientos destinados a coordinar acciones. Además, el bajo costo de los terrenos en el Dpto. Rawson ha favorecido la localización de núcleos habitacionales destinados a sectores de medios y bajos recursos lo que coadyuva al crecimiento urbano del Gran San Juan en la dirección Sur. 
Las razones que pueden explicar, en parte, por qué este fenómeno urbano se produce con más fuerza en esta orientación que en el resto de las direcciones, se refieren a que:

$1^{\circ}$ - En el sentido Norte, donde se localiza el Departamento Chimbas, la presencia del Río San Juan representa una barrera natural para la extensión de la planta urbana.

$2^{\circ}$ - En la dirección Este, donde se localiza el Departamento Santa Lucía, se presenta una situación similar desde el punto de vista del medio natural, dadas las características del suelo con tendencia a la revenición de algunas zonas, que condiciona y produce una contención espontánea del límite urbano, y que preserva las tierras aptas para cultivos, uso del suelo predominante de amplios sectores de este Dpto.

$3^{\circ}$ - Hacia el Oeste, donde se ubica el Departamento Rivadavia, es el sector que conjuntamente con el Dpto. Rawson ha experimentado un importante crecimiento del área urbana favorecido por la preferencia de la población de ingresos medios y altos de localizarse en esta zona. Ello a su vez ha elevado el valor de los terrenos pues limita la localización de barrios destinados a sectores de medios y bajos recursos. Por otra parte hacia esta dirección no aparecen centros de atracción como la que ejerce la ciudad de Mendoza hacia el Sur. La estructura de subcentros hacia el oeste es débil y no alcanza a contrarrestar la alta concentración de actividades del área central y su extensión en el corredor Sur. A ello debe sumarse otros aspectos como los condicionantes de su medio natural, que presenta fallas geológicas, bajadas de crecientes, contrapendientes pronunciadas para riego y provisión de infraestructura de servicios y otros referidos a la localización de industrias contaminantes en la zona.

Atendiendo a las razones anteriores, se focaliza el estudio en el Dpto. Rawson donde se aplica la técnica DAFO (Debilidades - Amenazas - Fortalezas - Oportunidades) para trabajar en función de las siguientes variables con sus parámetros urbanos:

\section{1) Condicionantes naturales del suelo}

1.1) Características planimétricas.

1.2) Nivel Freático.

1.3) Características mecánicas.

\section{2) Condicionantes urbanísticos}

2.1) Usos del suelo: Residencial, Equipamiento generales y productivos.

2.2) Calidad de la Construcción.

2.3) Tejido urbano: Densidad y forma de ocupación del suelo, Terrenos vacantes: regularidad de los terrenos.

2.4) Vulnerabilidad sísmica urbana directa y funcional.

\section{3) Atributos de los Flujos}

3.1) Red Vial: Jerarquización, conectividad, dimensiones, extensión.

3.2) Redes de Infraestructura de Servicios: cobertura, capacidad, servidumbres. 


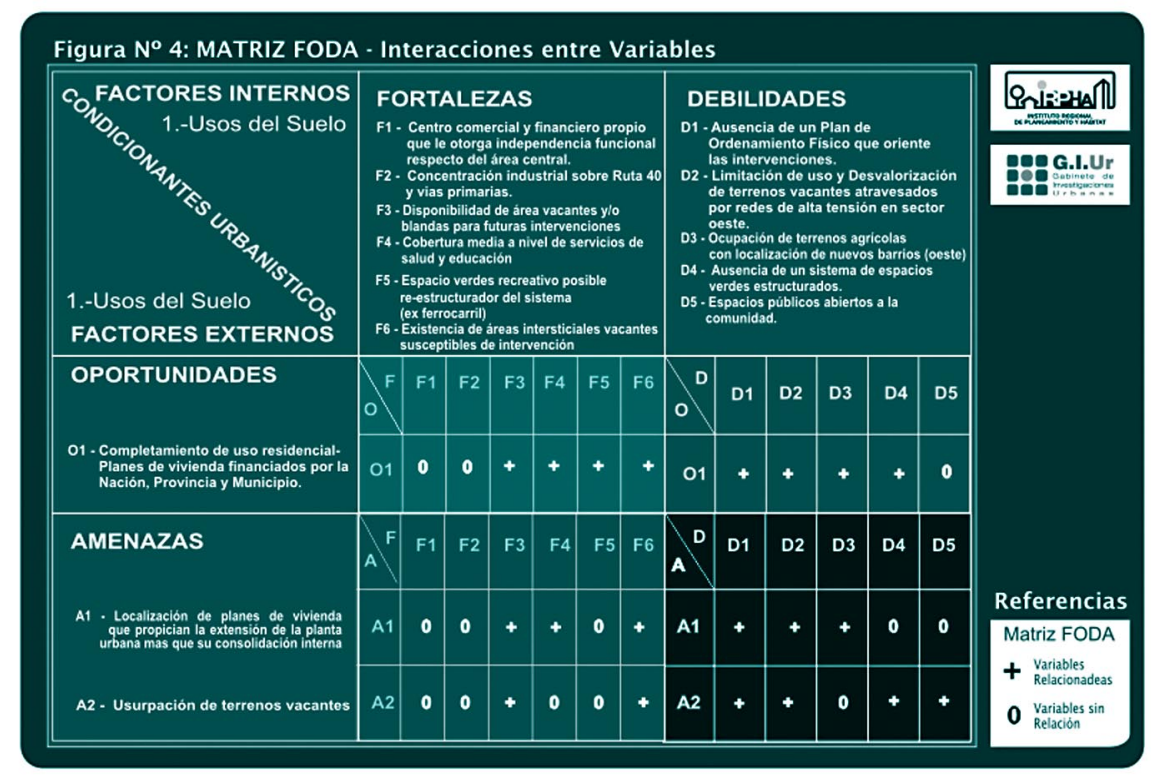

Como ya se mencionó, operativamente las tareas de análisis se apoyan el uso de un sistema de información geográfica. Se utiliza la capacidad del GIS para generar gamas cromáticas que resultan análogas a las categorías estadísticas analizadas, esto incrementa sensiblemente la legibilidad de los mapas resultantes.

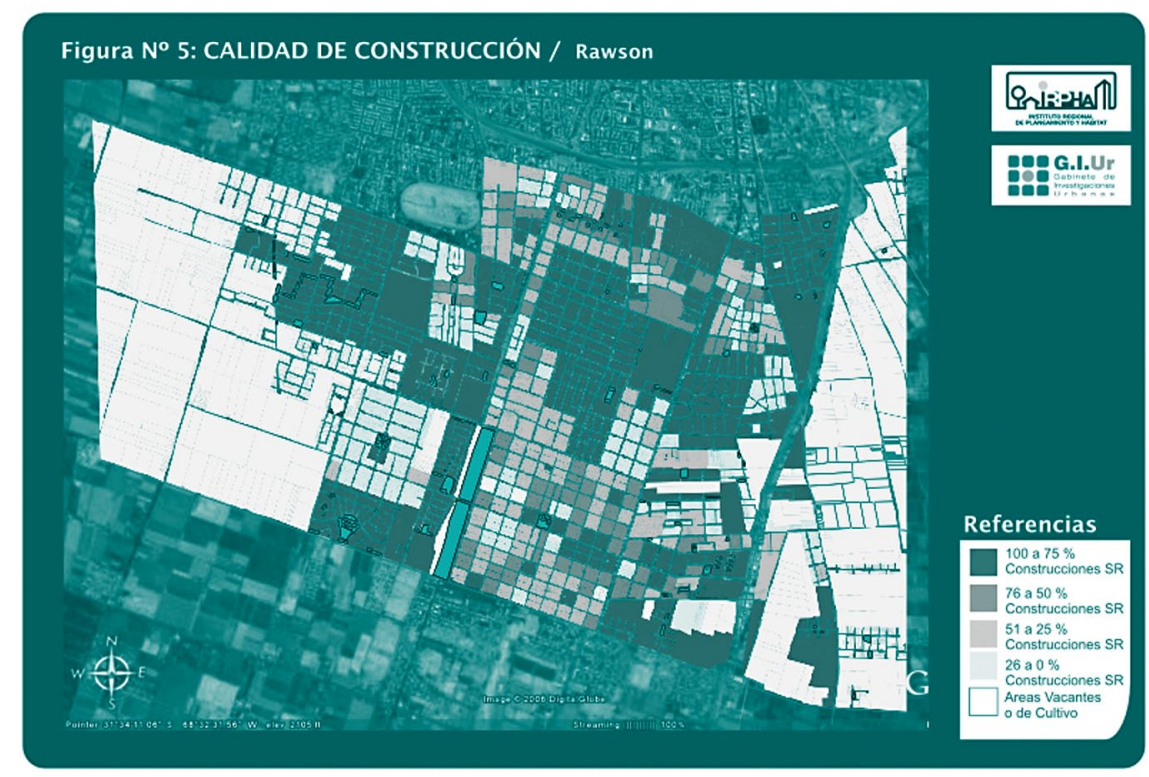

Con esta metodología es posible caracterizar el área de estudio y obtener una aproximación de la situación actual del Dpto. en el contexto del Gran San Juan, para avanzar a la etapa de definición de áreas prioritarias para la implementación de estrategias de intervención. La aplicación de estrategias alternativas permitirán minimizar las debilidades y amenazas o maximizar las fortalezas y oportunidades, detectadas en este momento de la investigación. 


\section{Estrategias Urbanas}

Se entienden como "áreas prioritarias" a los sectores urbanos que presentan grados importantes de deterioro físico y/o funcional ó se evidencian alteraciones en algunos elementos de su estructura interna. Es en estos sectores donde se considera necesario una intervención a través de distintas medidas determinadas como "sets de acciones" o estrategias, para revertir dicha situación, en plazos breves.

1 ROY, Andrés. Maestría en Gestión del Desarrollo Urbano Regional. FAUD- UNSJ. Año 1993.

"...Estrategia es la forma concreta para actuar en la trama urbana sin desconocer lo que ocurre en el campo social..."1

Las estrategias urbanas no constituyen un fin en sí mismas, son una etapa hacia la consecución de objetivos sociales, tales como el mejoramiento de las condiciones del hábitat residencial y urbano para la población. Implican la adecuación de determinados sectores de la ciudad a los requerimientos sociales de la comunidad involucrada. De este modo, las acciones estratégicas tienen incidencia no sólo físico espacial, sino también socio culturales.

La disponibilidad de tierras convenientemente localizadas, por lo general, es escasa. Las estrategias urbanas permiten, aparte de la recuperación del tejido social, recuperar tierras en áreas centrales y aledañas para la construcción de viviendas nuevas, en sectores subutilizados u ocupados con viviendas precarias y deterioradas. Con ese objetivo se pueden plantear estrategias de:

- Rehabilitación y Renovación para propiciar o incentivar la recuperación de áreas deterioradas por mala calidad de las construcciones o de tejido blando.

- Ocupación por densificación para aumentar niveles de densidad con construcción de nuevas viviendas.

- Contención del límite urbano a través de la urbanización y ocupación de terrenos vacantes y/o espacios intersticiales dentro del área urbana, para recuperar áreas servidas por infraestructura de servicios y con cobertura de equipamiento. Además de consolidar la planta urbana actual y detener la ocupación de áreas rurales adyacentes.

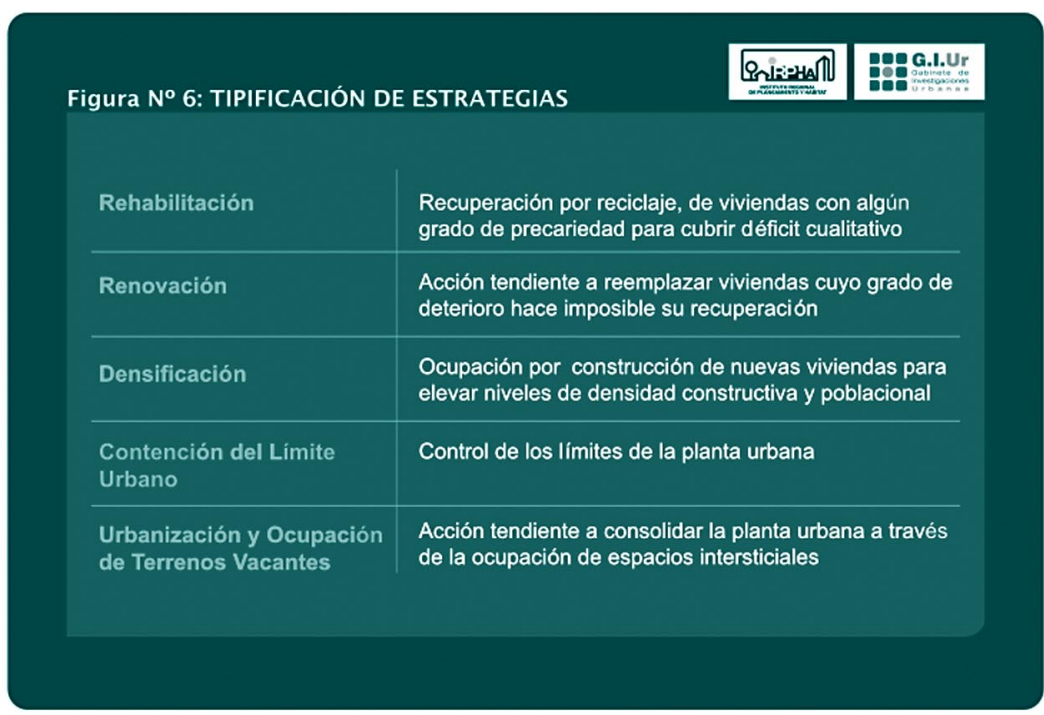




\section{Algunas Reflexiones Finales}

El presente estudio, circunscrito por su objetivo específico a la realización de tareas de prediagnóstico, no brinda, como es lógico, elementos para avanzar sobre aspectos propositivos. Sin embargo, los resultados de esta etapa, tienen aplicaciones directas en las siguientes de diagnóstico y determinación de áreas prioritarias de intervención.

Aunque la parte central del estudio se refiere al ámbito territorial del Dpto. Rawson, la interpretación de los resultados y conclusiones considera indefectiblemente su inserción en el contexto del Gran San Juan, pues los procesos urbanos tienen ámbitos socioterritoriales que exceden ó no reconocen límites jurisdiccionales. Además se configura en una suerte de marco teórico referencial que toma en cuenta las interacciones recíprocas entre estructuras físico-espaciales, socio-culturales y el soporte natural, dentro de un enfoque ambiental del desarrollo urbano.

Desde el punto de vista metodológico, el estudio considera unidades de análisis pequeñas, los radios censales, lo que permite que el análisis de los patrones de estructuración urbana estudiados se realice a gran nivel de desagregación espacial. La información cartográfica y los indicadores urbanos adoptados, incorporados al SIG, permiten la realización de estudios interrelacionados y simultáneos con la obtención de salidas estadísticas y mapeos que son la base para elaborar los elementos de este prediagnóstico y para la realización de las etapas posteriores.

Dentro de este marco de referencia, se considera que los procesos que provocan cambios estructurales que en la actualidad tienen lugar en las ciudades, conllevan a la profundización de los conflictos por la complejización de los problemas urbanos y la celeridad de esos procesos que los enmarcan. Esto determina la necesidad de definir acciones consensuadas, eficientes y eficaces que se materialicen a partir de una gestión pública innovadora que integre los diversos actores sociales que puedan aportar al tema, en este caso desde el ámbito académico, en búsqueda de un desarrollo urbano sustentable que asegure una mejor calidad de vida a la población \}

\section{Bibliografía}

DPDU - "Anillo Vial Periférico" - DPDU 2005

DPDU - "Metodología para Estudios de Renovación Urbana" 1998

DPDU - "Metodología para la Elaboración de Planes de Ordenamiento" - 1996

DPDU -"Estudio Comparativo de Límites Urbanos" 1990

GIUR - IRPHa - FAUD. "Estudio de Asentamientos Irregulares en el Gran SanJuan": Convenio de Cooperación y Asistencia Técnica entre la UNSJ y la Comisiónde Tierras Fiscales Nacionales. Programa ARRAIGO. Agosto / Noviembre de 1994

GIUR - IRPHa - FAUD. "Evolución de la Estructura Funcional y Espacial de la Ciudad de San Juan" . $1985 / 1989$

GIUR - IRPHa - FAUD. "Formulación de Estrategias Concretas para laPrevención Sísmica en el Área Urbana del Gran San Juan" - Área Temática 1: "La Prevención Sísmica como Proyecto Continuo de Desarrollo Urbano" 1997/1999

GIUR - IRPHa - FAUD. "Respuestas Físico Espaciales al Condicionante Sismo. Caso Dpto. Rawson". 1990

GIUR - IRPHa - FAUD. "Vulnerabilidad Sísmica Urbana. Estudio del Aspecto Funcional" 2000/2002

GCBA/FADU-UBA - "Plan Urbano Ambiental de la Ciudad de Bs. As." 1999

Roitman, Dora y Otros. "San Juan la Ciudad y el Oasis". EFU. San Juan, 1996.

Roy, Andrés. Maestría en Gestión del Desarrollo Urbano Regional. FAUD- UNSJ. Año 1993.

Google Earth - Imágenes Satelitales 2006

M 87 